\title{
El impacto del "carril-bici" de Sevilla sobre el espacio urbano de la ciudad: un análisis preliminar
}

\author{
The impact of Seville's cycle path on the urban space: \\ a preliminary analysis
}

\author{
Vicente Hernández-Herrador* y Ricardo Marqués** \\ Fecha de recepción: 12-04-2017 - Fecha de aceptación: 16-09-2017 \\ Hábitat y Sociedad (ISSN 2173-125X), n. ${ }^{\circ}$ 10, noviembre de 2017, pp. 181-202. \\ http://dx.doi.org/10.12795/HabitatySociedad.2017.i10.11
}

\begin{abstract}
The impact of newly created infrastructures in dense cities is a key element for assessing their integration in urban contexts. In the case of the network of cycle paths of Seville, this impact has been important in many aspects, and has been analyzed from several points of view. Nevertheless, as far as we know, an analysis of its direct impact on the urban space is still lacking. This analysis is essential in order to properly contextualize some debates that are presently taking place in the city with regard to such infrastructure. The present work develops a methodology for the analysis of the impact of the implementation of new bike paths on urban spaces through the quantitative evaluation of the net occupation of such spaces, linked to the creation of these infrastructures. This methodology is applied to the analysis of the basic network of cycle paths of Seville. The analysis shows that this process resulted in a net occupation of carriageways, followed by unpaved surfaces and pedestrian areas. The process has been, however, quite complex, its net result being the resultant of many interchanges between these categories. The analysis has led to the elaboration of a detailed cartographic database of these occupations, which we hope will be of interest for further analysis and planning processes. We are also confident that the methodology developed in this paper may be useful in other similar contexts.
\end{abstract}

\section{Key words}

Urban space management, Sustainable mobility, Bikeways, Seville

\section{Resumen}

El impacto de las infraestructuras de nueva creación en la ciudad consolidada es un elemento clave a la hora de evaluar su integración en la misma. En el caso de la red de vías ciclistas de Sevilla, este impacto ha sido considerable en muchos aspectos y ha sido analizado desde varios puntos de vista. No obstante, se echa de menos un análisis de su impacto directo sobre el espacio urbano, algo que resulta fundamental para contextualizar adecuadamente varios de los debates que están teniendo lugar en la ciudad en torno a dicha infraestructura. En este trabajo se desarrolla una metodología para el análisis de dicho impacto, a través de la evaluación cuantitativa de la ocupación neta de espacio urbano a consecuencia de las obras de reurbanización ligadas a la creación de la red básica de vías ciclistas de la ciudad. Del análisis se deduce que dicha ocupación ha sido un proceso complejo, que se ha traducido en una ocupación neta de calzada, seguida de superficie sin pavimentar y de zonas peatonales, por este orden, aunque mediante numerosos y complejos intercambios de usos en la superficie afectada. El análisis ha supuesto la elaboración de una base de datos cartográfica detallada de dichas ocupaciones, que esperamos sea de gran utilidad para ulteriores análisis y procesos de planificación. Asimismo, confiamos en que la metodología desarrollada pueda ser de utilidad para otros estudios similares.

\section{Palabras clave}

Gestión del espacio urbano; Movilidad sostenible; Vías ciclistas; Sevilla

\footnotetext{
* Consultor independiente. Santa Cleta Soc. Coop. And., C/ Fray Diego de Cádiz, 24, 41003 Sevilla. C.e.: vicenth_arq@hotmail.com.

** Universidad de Sevilla, Facultad de Física, Av. Reina Mercedes, s./n. 41012, Sevilla. C.e.: marques@us.es.
} 


\section{Introducción}

En Sevilla se ha venido desarrollando durante la última década un proceso de crecimiento de la movilidad ciclista contemporáneo de la construcción de una red de vías ciclistas segregadas (Marqués, 2011; Marqués et al., 2015; Castillo-Manzano et al., 2015), popularmente conocida como "el carril-bici", que ha supuesto el reconocimiento de la ciudad, a nivel nacional e internacional, como una de las ciudades de referencia en lo que a fomento de la movilidad ciclista se refiere. Entre los reconocimientos obtenidos, que certifican la alta valoración alcanzada en los diferentes ámbitos de la sociedad, se encuentran:

- Calificación "Best" en el $8 .{ }^{\circ}$ Concurso Internacional de Buenas prácticas de la ONU (Dubai, 2010);

- Mejor ciudad española para desplazarse en bicicleta según la revista Eroski Consumer (2013);

- Cuarto lugar en el prestigioso Copenhagenize Index of bycicle-friendly cities (2013);

- Mejor red de vías ciclistas de España según la revista OCU-Compra Maestra (2013);

- Ciudad mejor valorada por los usuarios de la bicicleta de España, según la revista OCU-Compra Maestra (2014).

No obstante, el desarrollo de esta red de vías ciclistas no ha estado exento de polémica, una polémica que ha estado ligada casi siempre a la ocupación de espacios peatonales y de todo tipo, como aparcamiento o zonas verdes, por la nueva infraestructura ciclista, algo por otra parte inevitable, dado que dicha infraestructura se ha ubicado necesariamente en su mayor parte sobre suelo urbanizado, con un uso muy consolidado en la mayoría de los casos. En este contexto resulta crucial un análisis objetivo de dichas ocupaciones de suelo urbano por la citada infraestructura, lo que constituye el principal propósito de este trabajo.

El debate acerca de las vías ciclistas y su verdadera aportación a la movilidad en bicicleta, no solo en Sevilla sino en todo el mundo, no es nuevo. En 1937, en un folleto del Cyclist's Touring Club, la asociación más influyente de los ciclistas británicos, podía leerse (citado en Horton, 2007, p. 143):

Es imposible escapar a la conclusión de que la mayor parte de la gente y de las organizaciones que abogan por la creación de vías ciclistas no lo hacen por benevolencia o por simpatía (hacia los ciclistas) [...]. Buena parte de la propaganda a favor de las vías ciclistas se basa en el deseo de eliminar a los ciclistas de la calzada [...].

Esta crítica no es infundada y tiene su base histórica en la actitud de muchos Gobiernos hacia el tráfico ciclista durante las décadas de 1920 y posteriores, cuando el automóvil comienza a ser promovido como "el transporte del futuro" en todo el mundo. Así, por ejemplo, en los Países Bajos, posiblemente el país europeo donde la bicicleta como modo de transporte ha tenido más éxito y ha recibido más atención por parte de las administraciones públicas a lo largo de la historia, la política de construcción de carreteras a partir de 1920 se centró en la promoción del automóvil privado; y las escasas vías ciclistas creadas en dicho período parecen responder más al deseo de eliminar de la carretera a 
los "molestos" ciclistas, que al de beneficiarlos. Así, al menos, parecía verlo la poderosa Asociación de Carreteras Holandesa (NWC por sus siglas en holandés) en las actas de cuyo primer congreso celebrado en 1920 podía leerse: "A fin de cuentas, la construcción de vías ciclistas a lo largo de las carreteras más importantes libera el tráfico a lo largo de estas de un elemento extremadamente molesto: el ciclista" (citado en The Dutch Bicycle Master Plan. Description and evaluation in an historical context, 1999, p. 22).

Estas críticas cristalizaron en un sector de las asociaciones ciclistas en lo que se ha dado en llamar la teoría del "ciclismo vehicular" (o vehicular cycling), cuyo máximo exponente ha sido John Forester, que fue presidente de la League of American Bicyclists, la asociación más influyente de los ciclistas en los EEUU. Esta escuela de pensamiento se opone de manera radical a la creación de vías ciclistas (ver Forester, 2001). En la obra citada, Forester llegó a escribir con relación a las especificaciones vigentes en EEUU acerca de las vías ciclistas:

Las especificaciones sobre vías ciclistas no fueron redactadas con el objetivo de reducir la accidentalidad de los ciclistas [...]. La única consideración fue como limpiar de ciclistas los carriles del tráfico motorizado, sin dañar a los ciclistas hasta el punto de que el Gobierno llegara a ser responsable legal por sus lesiones.

Es evidente que la situación en Sevilla en el año 2006, cuando comienza la construcción de la actual red de vías ciclistas, no es en nada comparable a la de los Países Bajos en 1920. Por aquellas fechas, en los Países Bajos, el 74\% del tráfico correspondía a las bicicletas, mientras que solo el $16 \%$ correspondía a automóviles y motocicletas (The Dutch Bicycle Master Plan. Description and evaluation in an historical context, 1999). Por su parte, en Sevilla, en 2006, el tráfico ciclista era prácticamente inexistente y difícilmente se podía pensar que la construcción de las nuevas vías ciclistas respondiera al deseo de eliminar definitivamente de la calzada a los escasos ciclistas que todavía circulaban por ella. Así, por ejemplo, la Encuesta Domiciliaria de Movilidad de 1990, que contiene el último dato disponible acerca del reparto modal en bicicleta anterior a 2006, evaluaba el uso de la bicicleta en 12741 desplazamientos diarios (citado en Marqués, 2017, p. 158), el 0,6\% del total de los desplazamientos del Área Metropolitana, que en 1990 agrupaba a 980000 personas, de las cuales el $68,5 \%$ vivían en el municipio de Sevilla.

No obstante, es un hecho comprobable todos los días en nuestro país que la construcción de nuevas vías ciclistas en zonas urbanas consolidadas, como ha sido casi siempre el caso en Sevilla, plantea el dilema de construirlas sobre la calzada o fuera de ella; en muchos casos sobre aceras o zonas peatonales. Por tanto, es importante cuantificar, en el marco del debate mencionado, hasta qué punto el proceso de reurbanización asociado a la creación de la red de vías ciclistas de Sevilla se saldó con pérdida de espacio peatonal y/o de espacio para la circulación y el aparcamiento de vehículos a motor. En el primer caso estaríamos ante la confirmación de que, efectivamente, uno de los objetivos de la creación de la red de vías ciclistas pudo ser, en palabras de Forester, "limpiar de ciclistas los carriles del tráfico motorizado”. En el segundo caso, dicha hipótesis resultaría difícilmente sostenible, siendo evidente que los cambios de uso del suelo ligados a la construcción de las vías ciclistas fueron coherentes con una filosofía 
de promoción de la movilidad urbana sostenible. Este debate, como ya hemos mencionado, no es privativo del caso de Sevilla, sino que se halla presente, de manera general, en cualquier actuación que implique creación de vías ciclistas en un entorno urbano a lo largo del mundo. Por tanto, es de sumo interés la elaboración de una metodología que permita cuantificar el resultado de la creación de redes urbanas de vías ciclistas en términos de perdida/ganancia de espacio peatonal y/o calzada.

En el caso de Sevilla también se generó un intenso debate social en torno a los conflictos entre ciclistas y peatones que afloraron tras la construcción de la red de vías ciclistas (Malpica-Soto, 2010; CastilloManzano y Sánchez-Braza, 2013). De modo que, aun siendo cierto que los accidentes entre ciclistas y peatones siguieron siendo un porcentaje relativamente pequeño de la accidentalidad global tanto de unos como de otros (SIBUS, 2016), se produjo una situación en la que tanto los portavoces más escuchados de los peatones como los propios ciclistas (SIBUS, 2012) situaron los conflictos entre ambos modos como uno de los principales problemas a que se enfrentaba la naciente movilidad ciclista de la ciudad.

Esta problemática no es, de nuevo, exclusiva de Sevilla. Es cierto que los accidentes de tráfico entre peatones y ciclistas suelen ser, cuantitativamente, una pequeña parte de la accidentalidad global tanto de peatones como de ciclistas en casi todos los países del mundo, incluyendo países tan alejados unos de otros, geográfica y culturalmente, como España (Dirección General de Tráfico, 2010) o Australia (Chong et al., 2010). No obstante, cualitativamente, dicho tipo de conflictos no cesan de producir continuos debates en la sociedad y aparecen sistemáticamente como una parte central de la problemática ligada a la expansión de la bicicleta como vehículo urbano. No se trata de un fenómeno nuevo. Ya a principios del siglo XIX, cuando el carrocero inglés Dennis Johnson popularizó en Londres su "Hobby Horse", una versión mejorada de la "Draisiana" inventada por Karl Drais en 1817, los conflictos entre los peatones y los ciclistas que circulaban por las aceras a bordo de sus "Hobby Horses" provocaron varias sentencias condenatorias y desembocaron en la prohibición generalizada de circular en "Hobby Horse" por la acera (Herlihy, 2004, p. 38).

En el debate mencionado también ocupa un lugar central la posible ocupación por los ciclistas de las aceras y el espacio peatonal. Esto incluye la posible ocupación de dicho espacio para la construcción de vías ciclistas, lo que nos lleva de nuevo al dilema, ya citado, de construir las vías ciclistas a costa de la calzada o a costa del espacio peatonal preexistente. Aunque esta sea solo una parte del problema, la manera en que se resuelva dicho dilema depende, en gran medida, de la intensidad y de la cualidad de los conflictos entre ciclistas y peatones que, por otro lado, inevitablemente han de surgir tras la masiva aparición en la vía pública de un nuevo vehículo como la bicicleta.

El desarrollo de la red de vías ciclistas de Sevilla ha sido abordado en la literatura científica desde muchos puntos de vista: desde el histórico-descriptivo (Marqués, 2011; Marqués et al., 2014: Marqués et al., 2015; Marqués, 2017, pp. 153 y ss.); desde el análisis sociológico y psicológico de los diversos actores del proceso (Malpica-Soto, 2010; Castillo-Manzano y Sánchez-Braza, 2013; Fernández-Heredia et al., 2014); desde la resiliencia del proceso (Morales-Carballo, 2011) y de la etnografía (Huerta y Hernández-Ramírez, 2015); así como desde el análisis de aspectos concretos del proceso, como el desarrollo del sistema 
de bicicletas públicas (Castillo-Manzano y Sánchez-Braza, 2013b; Castillo-Manzano et al., 2015; López-Valpuesta y Sánchez-Braza, A., 2016), la relación entre la movilidad ciclista y el transporte público (Marqués et al., 2015b) o el impacto en la seguridad vial (Marqués y HernándezHerrador, 2017). Sin embargo, han sido pocos los estudios acerca del impacto de las nuevas vías ciclistas sobre el espacio urbano en general y de su reparto entre calzada y zonas peatonales en particular. A este respecto, apenas si hay algún estudio parcial (A Contramano, 2009). También a escala internacional son prácticamente inexistentes los análisis con una temática similar. En este trabajo pretendemos desarrollar una metodología para el estudio de dicho impacto, aplicándola al análisis de la red de vías ciclistas de Sevilla.

A fin de acotar el problema nos hemos limitado a analizar la denominada "red básica", de $77 \mathrm{~km}$ aproximadamente, definida en el Plan de la Bicicleta de Sevilla 2007-2010 (Ayuntamiento de Sevilla, 2007), cuya construcción se desarrolló fundamentalmente durante los años 2006 y 2007 (Marqués et al., 2015) y cuyo plano esquemático reproducimos en la Figura 1. Con anterioridad a esas fechas, solo se habían desarrollado algunas actuaciones de mucha menor magnitud en la ciudad. En el año 1980 se pintó un carril-bici mono-direccional de 350 metros en la céntrica calle de San Fernando, frente al Rectorado de la Universidad, que tiene como único mérito haber sido el primer carril-bici de la ciudad. Dicha infraestructura duró hasta 1985, cuando el citado carril-bici fue eliminado definitivamente (Marqués, 2017, p. 162). Con posterioridad a esa fecha se redacta el primer plan de vías ciclistas de la ciudad (Mateos et al., 1987) que, sin embargo, no llega a ejecutarse debido a un inoportuno cambio de gobierno en la ciudad (Marqués, 2017, p. 162). Posteriormente, en el año 1993, se redacta un plan especial de la bicicleta por la Gerencia de Urbanismo (Gerencia de Urbanismo de Sevilla, 1993), que es aprobado en 1994. Este plan incluye dos proyectos de vías ciclistas de recreo, una a lo largo del nuevo paseo en la orilla izquierda del río Guadalquivir y otro por el histórico parque de María Luisa, que no se llega a realizar. Además, incluye el mapa de una futura red de vías ciclistas por la ciudad, cuyo diseño y realización práctica no se concretan. Con posterioridad a la elaboración de dicho plan se ejecutan algunas vías ciclistas de transporte, aparentemente en cumplimiento del plan mencionado, hasta un total $12 \mathrm{~km}$ en el año 2004, que con posterioridad se incorporan en su mayor parte a la red de vías ciclistas de la ciudad. Como ya hemos mencionado, nuestro análisis se circunscribe a la citada red básica de vías ciclistas, de $77 \mathrm{~km}$ de longitud (Marqués et al., 2015), la mayoría de las cuales fueron construidas con posterioridad a 2006, tal y como se puede apreciar en el Figura 1, en cuyo inset se muestran las vías ciclistas existentes con anterioridad a 2006, diferenciando entre aquellas que se incorporaron a la red básica objeto de nuestro análisis y las que no.

Teniendo en cuenta que la red de vías ciclistas de la ciudad alcanza en la actualidad una longitud cercana a los $170 \mathrm{~km}$ (Ayuntamiento de Sevilla, 2013), es evidente que el presente análisis es solo de una primera aproximación al problema. No obstante, como puede verse en la propia Figura 1 y se detalla en Marqués et al. (2015), la mencionada "red básica" configuró ya la estructura de la futura red ciclista de la ciudad, de modo que su análisis puede darnos una primera idea acerca de cómo su construcción fue abordada por el Ayuntamiento. Estudios posteriores, referidos al resto de la red, podrán darnos, una vez finalizados, una visión más completa de la cuestión. 


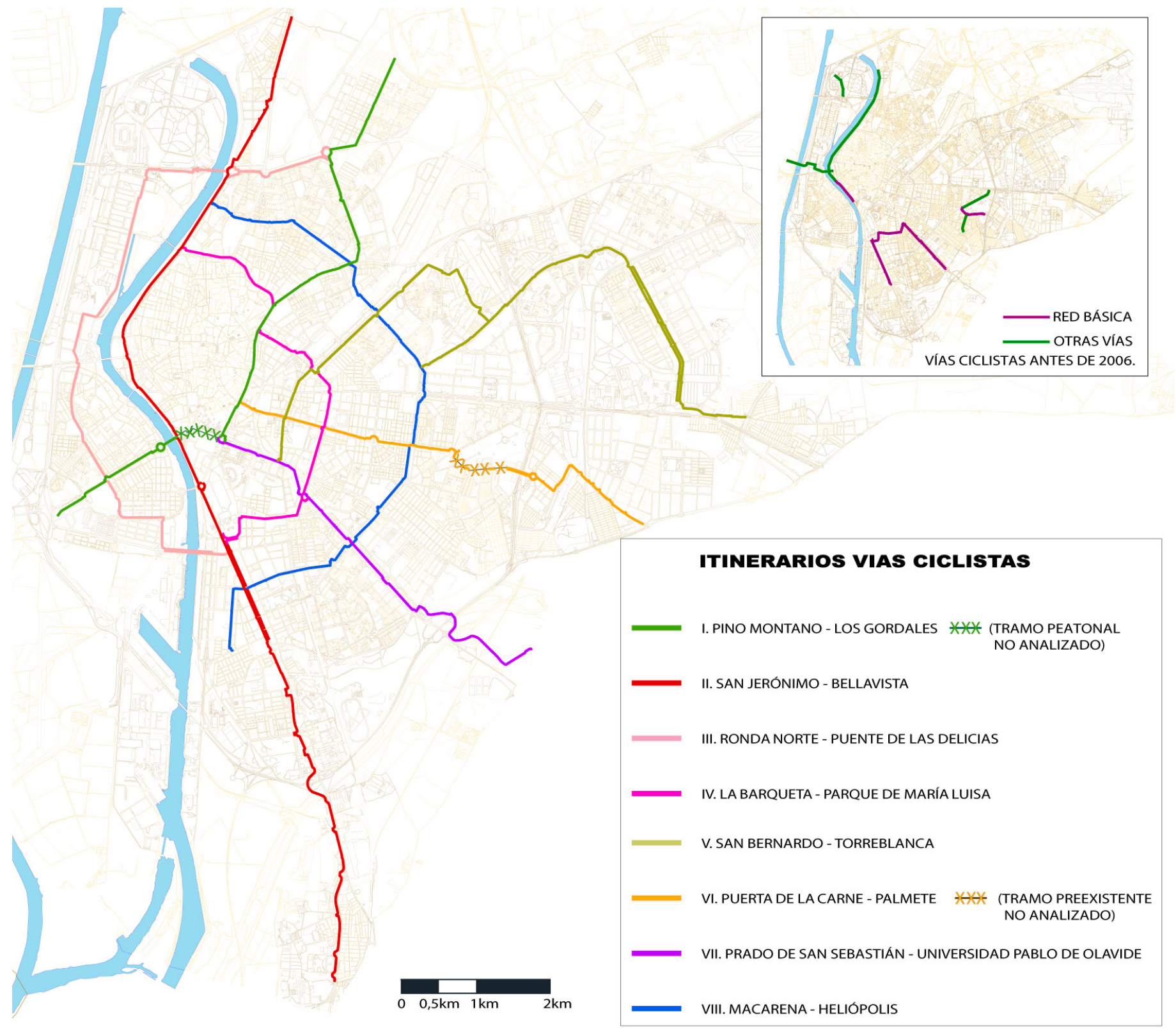

Figura 1. Red básica de vías ciclistas de Sevilla. En el inset se muestran las vías ciclistas existentes con anterioridad a 2006. Fuente: Ayuntamiento de Sevilla y elaboración propia
Antes de pasar al análisis, sería conveniente exponer de manera sucinta algunos datos y resultados previos que ayuden a contextualizar adecuadamente los resultados del presente estudio. La red de vías ciclistas de Sevilla está formada en la actualidad por carriles-bici a nivel de la calzada $(9,8 \%)$, aceras-bici $(61,8 \%)$, pistas-bici $(11,3 \%)$, sendasbici $(9,6 \%)$ y vías compartidas $(7,5 \%)$ (Ayuntamiento de Sevilla, 2013). Ello implica que solo el $9,8 \%$ del total de las vías ciclistas discurre al nivel de la calzada, lo que puede dar la impresión de que la práctica totalidad de las vías ciclistas se han realizado a costa de espacios peatonales. Sin embargo, como veremos más adelante, ello dista de ser así. Tal peculiaridad se debe a que buena parte de las vías ciclistas a nivel del acerado se han realizado mediante la ampliación de este para incorporar la vía ciclista, eliminando o reformando bandas de aparcamiento en la mayoría de los casos (A Contramano, 2009; Marqués, 2011), de ahí la importancia del presente análisis para caracterizar adecuadamente el balance neto de la ocupación del espacio urbano por las vías ciclistas.

La mayoría de las vías ciclistas de Sevilla son bidireccionales, con una anchura de 2,5 m, y todas están segregadas del tráfico motorizado, bien sea por su disposición al nivel del acerado o mediante separadores 
discontinuos cuando la vía ciclista discurre al nivel de la calzada (Marqués, 2011). La segregación de los flujos peatonales en las vías que discurren por la calzada se realiza mediante un pavimento diferenciado, de diferente color y textura. A menudo se utiliza el propio arbolado u otra vegetación sobre el acerado para reforzar esta separación (ob. cit.). Podemos también afirmar, a partir de la Figura 1, que la red básica de vías ciclistas fue un primer paso relevante hacia el cumplimiento de los objetivos relativos a la movilidad ciclista contenidos en el Plan Especial de Indicadores de Sostenibilidad Ambiental de la Actividad Urbanística de Sevilla (Agencia de Ecología Urbana de Barcelona, 2007), que se fueron cumpliendo con posterioridad a medida que la red se fue densificando en actuaciones posteriores (Marqués, 2017).

En cuanto al uso de la red de vías ciclistas, este alcanzó su valor más elevado en el año 2011, con 72000 desplazamientos diarios (SIBUS, 2012), para luego descender levemente a 62000 desplazamientos diarios en 2015 (SIBUS, 2016). Estos datos se deducen de conteos efectuados en días laborables sin lluvia a lo largo de diversos puntos de la red y de los datos de uso del sistema de bicicletas públicas de la ciudad. Los 72000 desplazamientos diarios citados se estima que corresponden a una participación modal de la bicicleta sobre el total de desplazamientos motorizados del 9\%, o del 5,6\% sobre el total de desplazamientos, incluyendo los desplazamientos peatonales (SIBUS, 2012).

Para evaluar la densidad de uso del viario sobre el que se asienta la red ciclista disponemos de datos pormenorizados y actualizados acerca del índice medio diario del tráfico motorizado en las principales vías de la ciudad, a través de la página web de la Delegación de Movilidad. ${ }^{1}$ En cuanto a la movilidad ciclista, disponemos de los sucesivos conteos manuales llevados a cabo por el Ayuntamiento de Sevilla entre 2006 y 2009 (Ayuntamiento de Sevilla, 2006; 2007b; 2008; 2010) y por el SIBUS entre 2011 y 2015 (SIBUS, 2012; 2014; 2016), así como de los datos proporcionados por los eco-contadores instalados por el Ayuntamiento de Sevilla en 10 puntos de la red de vías ciclistas que, desde 2009, aunque con periodos de inactividad, nos ofrecen datos del flujo de desplazamientos ciclistas en tales vías. Lamentablemente no disponemos de datos cuantitativos acerca de los flujos peatonales en dichas arterias, algo esencial para llevar a cabo un análisis comparativo de la movilidad peatonal y ciclista. No obstante, en general se puede afirmar, tanto a partir de los datos disponibles como de la inspección visual, que hay una clara correlación entre el volumen de los tres tráficos (motorizado, ciclista y peatonal) en las diferentes avenidas de la ciudad dotadas de vía ciclista. El tráfico ciclista más denso se produce en la denominada Ronda Histórica (eje Resolana, Muñoz León, Capuchinos, María Auxiliadora, Recaredo, Menéndez y Pelayo, Avenida del Cid $)^{2}$ que rodea por el este el casco histórico de la ciudad, al que se refiere uno de los estudios ya mencionados (A Contramano, 2009), así como en el Paseo de las Delicias, donde se detectan flujos de entre 4000 y 5000 ciclistas diarios. En algunos puntos del eje mencionado, la densidad del tráfico ciclista (medida en pasajeros por metro de sección del viario correspondiente a cada modo) llega a superar la del tráfico motorizado privado (Parody, 2011).

En cuanto a las otras redes sinérgicas con la bicicleta cuyo crecimiento, en detrimento del espacio dedicado prioritariamente al automóvil privado, se plantea como objetivo para el desarrollo de una movilidad más sostenible, sus previsiones de desarrollo se detallan en el Plan General de Ordenación Urbana de la ciudad (Ayuntamiento
$1 \quad$ Recuperado el 21 de junio de 2017 de: http://trafico.sevilla.org/imd.html. 2 Consideramos que el lector interesado puede localizar geográficamente estas zonas con la ayuda de Google Map o cualquier otro mapa interactivo en Internet, por lo que en lo sucesivo utilizaremos con libertad la nomenclatura del callejero de Sevilla para identificar zonas de la ciudad. 
de Sevilla, 2006), concretamente en los planos de ordenación o.e.06 (transporte público) y o.e.08 (ejes ciclistas y peatonales). Las previsiones de desarrollo de la red de transporte público incluyen el tranvía (o metrocentro), la red de metro de Sevilla, la red de carriles-bus y el cierre del anillo de cercanías, y se han desarrollado hasta la fecha de manera desigual, siendo llamativo el parón experimentado por la red de metro, de la que solo se ha realizado la Línea 1, y el escaso desarrollo de la red de carriles-bus. En cuanto a los ejes peatonales y ciclo-peatonales (plano o.e.08 citado), apenas se han desarrollado, en lo que constituye uno de los déficits más llamativos en el desarrollo del PGOU de Sevilla. De modo que podemos afirmar que la red de vías ciclistas ha sido el único componente de las redes de movilidad activa que se ha desarrollado hasta la fecha de un modo significativo.

No obstante, es necesario mencionar también que, simultáneamente a la construcción de la red de vías ciclistas, se llevaron a cabo una serie de actuaciones que supusieron un notable aumento de las áreas peatonales de la ciudad, si bien no directamente ligadas a un plan global de creación de una red de ejes peatonales por toda ella, como fue el caso del carril-bici en relación con la bicicleta. Estas actuaciones tuvieron un impacto en la estructura del espacio urbano muy importante, suponiendo un crecimiento neto en cantidad y calidad del espacio peatonal que muy posiblemente supere con creces las posibles pérdidas debidas a otras actuaciones, incluyendo la creación del carril-bici. Sería preciso analizar y tener en cuenta este hecho para enmarcar adecuadamente el impacto sobre el espacio peatonal del conjunto de políticas que propiciaron la creación de la red de vías ciclistas. Dicho análisis queda, sin embargo, fuera del ámbito del presente trabajo.

\section{Metodología}

La "red básica" de vías ciclistas de Sevilla supuso la realización de una serie de obras que cambiaron drásticamente el paisaje urbano de la ciudad, al incorporar a este un nuevo viario antes prácticamente inexistente, en la forma de una banda segregada del tráfico motorizado y pavimento diferenciado - el "carril-bici" - que recorría y estructuraba la ciudad. Para ello hubo que reurbanizar buena parte de las vías públicas por las que discurría dicha infraestructura, eliminando a veces la calzada, a veces aceras y a veces superficie sin pavimentar (más adelante definiremos estos conceptos con mayor precisión), pero también generando a veces aceras, calzada o zonas sin pavimentar, conforme a las necesidades de la mencionada reurbanización. En general, podemos escribir:

$$
\Delta \mathrm{CB}+\Delta \mathrm{C}+\Delta \mathrm{A}+\Delta \mathrm{SP}=0
$$

donde $\Delta \mathrm{CB}$ es el incremento de superficie dedicada a vía ciclista, $\Delta \mathrm{C}$ es el incremento neto de superficie dedicada a calzada (incluyendo aparcamiento), $\Delta \mathrm{A}$ es el incremento neto de acerados y $\Delta \mathrm{SP}$ el incremento neto de espacios sin pavimentar, cantidades que pueden ser positivas o negativas.

Para el cálculo de las magnitudes contenidas en la Eq. 1 se analizaron las vías por donde se trazó la red básica de vías ciclistas (Figura 1) y su estado antes del inicio de las obras en el año 2006, se comparó con el estado en que se encontraban estas calles en el año 2014. Conviene 
aclarar que esto no supone estrictamente un análisis de la implantación de la red de itinerarios ciclistas, sino de su estado final, incluyendo las diferentes obras y reformas que se acometieron, tanto en las vías ciclistas como en el resto del viario, hasta el año 2014.
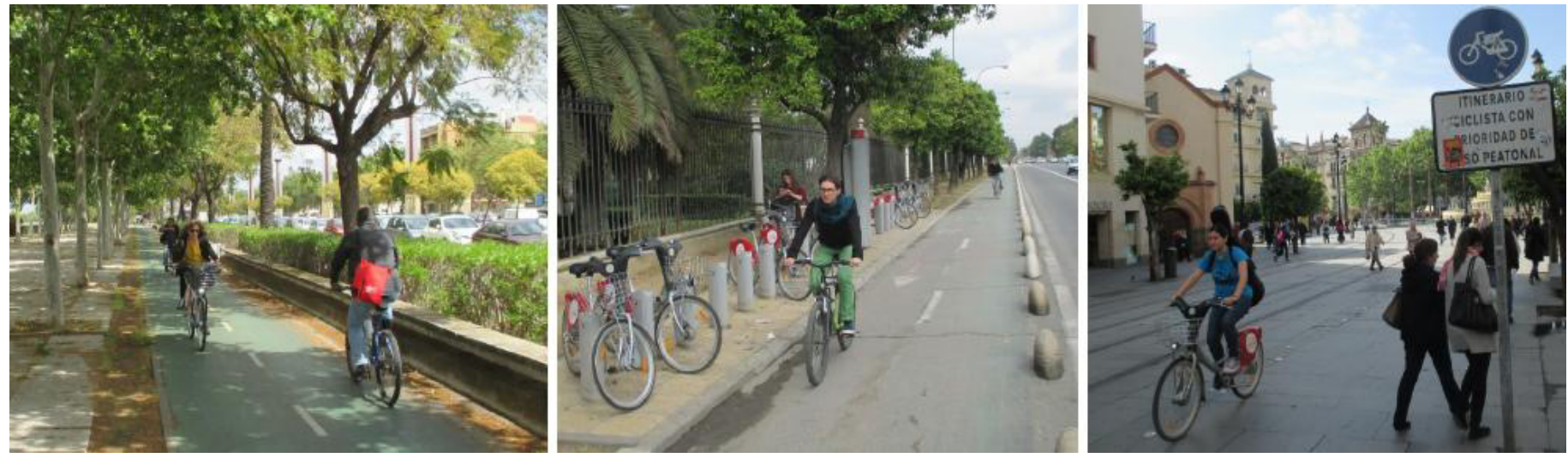

El análisis tuvo varias fases. La primera fase consistió en la realización de un recorrido por toda la red recogiendo en vídeo georreferenciado el estado y situación real de las vías ciclistas en el espacio público. La segunda fase consistió en la búsqueda de la cartografía digital que permitiera realizar el análisis de las vías ciclistas. La biblioteca de la Escuela Técnica Superior de Arquitectura de Sevilla proporcionó la cartografía de la ciudad realizada por la Gerencia de Urbanismo, utilizada en las fases finales de la redacción del PGOU, actualizada al año 2004. La Gerencia de Urbanismo de Sevilla proporcionó una cartografía digital que incluía las capas de línea de fachada, carril-bici y línea de acera de la ciudad de Sevilla, actualizada al año 2013. En el año 2012 el sistema de referencia utilizado en la Gerencia de Urbanismo de Sevilla cambió del sistema ED50 UTM Zona $30 \mathrm{~N}^{3}$ al actual ETRS89 UTM Zona $30 \mathrm{~N} .{ }^{4}$ Por ello fue necesario adaptar el sistema de referencia de las cartografías más recientes al sistema antiguo con el que se elaboró la cartografía de 2004.

La tercera fase consistió en la corrección de las cartografías, para lo que se utilizó el GeoPortal de la Gerencia de Urbanismo de Sevilla, ${ }^{5}$ que permitió actualizar la cartografía digital más reciente. Pese a ello, aún hizo falta realizar levantamientos in situ, ya fuese por falta de actualización en la información recogida en el GeoPortal, como por errores en los datos. La cartografía de 2004 se corrigió para que representase con la mayor precisión posible la situación previa al inicio de las obras de la red básica de itinerarios ciclistas en el año 2006. Para estas correcciones se utilizó el histórico de imágenes aéreas disponibles a través de las herramientas de la empresa Google Inc., además de otras fuentes cartográficas.

La cuarta fase supuso el análisis comparativo propiamente dicho. Este análisis consistió en la superposición de la cartografía del estado "actual" sobre la cartografía anterior al inicio de las obras. Para este análisis se caracterizó el espacio público en los cuatro tipos ya mencionados: vía ciclista, acera, calzada y espacio sin pavimentar, según las siguientes definiciones:

- Vía ciclista: son los espacios delimitados para la circulación de bicicletas. En esta definición se incluyen los tramos compartidos con los peatones, siempre que quede delimitado el carril por el que deben circular las bicicletas. También se incluyen los cruces
Figura 2. Los tres tipos de vías ciclistas analizados en este estudio. De izquierda a derecha, tramo de vía ciclista a nivel del acerado (C/ Torneo), vía ciclista segregada en la Calzada (Paseo de las Delicias) e itinerario ciclista señalado con tachuelas metálicas (Avenida de la Constitución). Fuente: elaboración propia.

3 European Datum 1950 (ED50), constituido por el Elipsoide Internacional de Hayford 1924 (semieje mayor 6.378.388 m. y aplanamiento de 1/297), con Datum Postdam y orígenes de las coordenadas geodésicas, para las latitudes el Ecuador y para las longitudes el meridiano de Greenwich. Se representa en la proyección Universal Transversa de Mercator (U.T.M.). Zona 30N.

4 Sistema de Referencia Terrestre Europeo 1989, que tiene asociado el elipsoide GRS80. Se representa en la proyección Universal Transversa de Mercator (U.T.M.). Zona 30N

$5 \quad$ Recuperado el 21 de junio de 2017 de: http://sig.urbanismosevilla.org/ GeoPortal.aspx. 
sobre la calzada, siempre que estén señalizados como carril-bici o cruce ciclista. Los tres tipos fundamentales de vías ciclistas considerados se muestran en la Figura 2.

- Acera: es la superficie peatonal urbanizada. Esto incluye las aceras compartidas con los ciclistas y de prioridad peatonal, pero no los espacios delimitados de algún modo como vía ciclista sobre la acera, incluso si sobre dichas vías ciclistas se ha determinado la prioridad de paso peatonal.

- Calzada: es la superficie destinada a la circulación de los vehículos no incluida en las vías ciclistas, incluyendo los aparcamientos en superficie.

- Espacio sin pavimentar: en esta categoría se han incluido los parterres (superficie de terrizo o albero), alcorques, solares y terrenos que sufrieron una transformación urbana de suficiente calibre como para alterar sustancialmente sus condiciones iniciales.

Para establecer el ámbito de afección de la obra del carril-bici se establecieron una serie de criterios respecto al espacio urbano en el que se situaba la vía ciclista:

- Calles tradicionales (acerado a ambos lados de una calzada central): se consideró que la vía ciclista solo afectó al lado en que se sitúa respecto al eje central de la calzada. Por tanto, en el caso de las vías bidireccionales, solo se analizó el lado de la calle en el que se situó la vía ciclista.

- Boulevard: en los casos en que la vía ciclista discurre por un boulevard o isleta central de una gran avenida solo se analizaron los cambios producidos en dicho elemento respecto a los ejes de las calzadas que lo flanquean.

- Nuevos viarios: en los casos en que se puede entender que el espacio urbano no se transformó para incluir la vía ciclista, sino que esta se incorporó a su propio diseño desde el principio, no se hizo un análisis de los cambios del espacio urbano. Solo se analizó la superficie que ocupa la vía ciclista y la correspondiente a cruces señalizadas sobre la calzada, que se consideró como pérdida de espacio sin pavimentar. Esta situación aparece en los nuevos desarrollos urbanos, como la zona norte de San Jerónimo o la reurbanización de la travesía de Bellavista.

- Grandes peatonalizaciones: como ya hemos mencionado, coincidiendo con la construcción de la red de vías ciclistas, la ciudad acometió una campaña de grandes peatonalizaciones. Los tramos de vías ciclistas situados en estas zonas no se han contemplado en el análisis, ya que la inclusión en el mismo de una transformación tan desproporcionada de calzada en espacio peatonal alteraría los resultados de este trabajo, convirtiéndose en un factor de confusión. En nuestro caso (ver Figura 1), esto afecta solamente al itinerario ciclista sobre la calle San Fernando, que se ha marcado con cruces en dicha figura.

- Vias ciclistas existentes antes de 2006: cuando alguna de estas vías ciclistas se ha incorporado a la red básica y se disponía de cartografía adecuada para ello, las ocupaciones de espacio ligadas a la construcción estas vías se han analizado según la metodología descrita. Solo en aquellos casos en que no se pudo disponer de la citada información cartográfica, las vías anteriores a 2006 no se han analizado. En la práctica esto afecta solamente a un pequeño 
tramo de vía ciclista en las proximidades del parque Amate (vid. Figura 1 y Tabla 2 más adelante).

El resultado de la aplicación de la metodología descrita ha sido, como ya hemos mencionado, una base de datos cartográfica que recoge todas las transformaciones y cambios de uso del suelo referidas. Como ejemplo del alcance de dicho estudio, la Figura 3 recoge un esquema del análisis realizado en una de las zonas estudiadas, en particular del análisis realizado en la intersección entre las calles República Argentina y la calle Miño. En la imagen puede verse la complejidad del proceso de cambio de uso de los suelos afectados por la obra de construcción del carril-bici, ilustrándose la metodología aplicada.

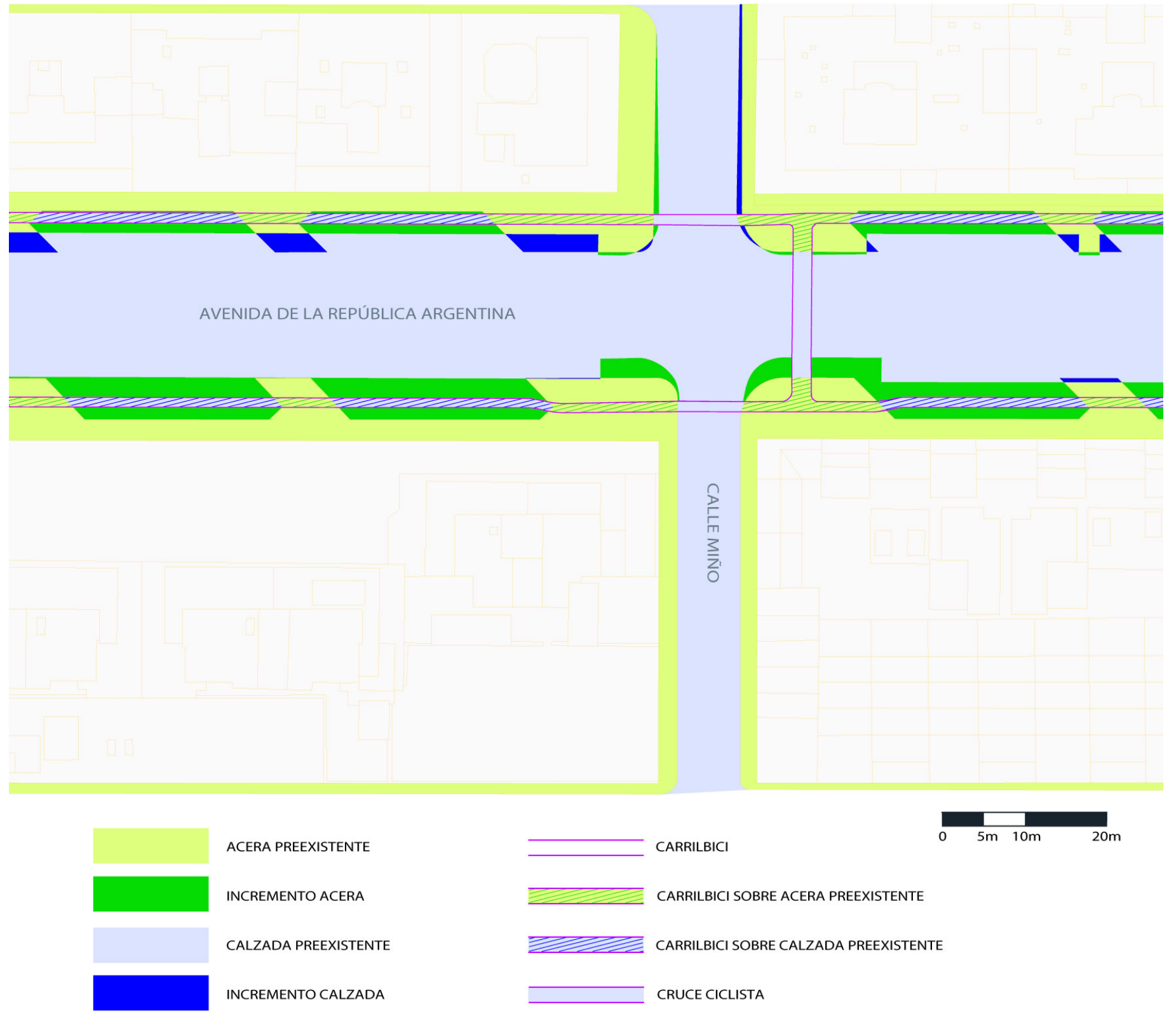

\section{Resultados del análisis}

Las grandes cifras correspondientes al análisis realizado se resumen en la Tabla 1, donde se reflejan los diferentes incrementos de la Eq. 1, desglosados por itinerarios. La Tabla 1 muestra que, globalmente, el pro-
Figura 3. llustración de las ocupaciones y cambios de uso de los suelos ligadas a la construcción del carril-bici en la intersección entre la avenida de la República Argentina y la calle Miño. Fuente: elaboración propia. 
ceso de reurbanización asociado a la creación de la red de vías ciclistas tuvo como consecuencia, en primer lugar, una notable pérdida de superficie de calzada ( $53 \%$ ), seguida por una notable urbanización de superficie sin pavimentar (38\%) y una pérdida de superficie peatonal (mayoritariamente aceras) que supuso el $9 \%$ de la superficie de vías ciclistas generada.

\begin{tabular}{|c|c|c|c|c|c|c|}
\hline & $\Delta \mathbf{C B}\left(\mathbf{m}^{2}\right)$ & $\Delta \mathbf{A}\left(\mathbf{m}^{2}\right)$ & $\Delta \mathrm{C}\left(\mathbf{m}^{2}\right)$ & $\Delta \mathbf{S P}\left(\mathbf{m}^{2}\right)$ & Error $\left(\mathbf{m}^{2}\right)$ & Error (\%) \\
\hline Itinerario I & 19822,90 & $-3364,36$ & $-15141,43$ & $-8046,33$ & $-0,49$ & $-0,0025 \%$ \\
\hline Itinerario II & 35546,17 & $-10195,95$ & $-9201,62$ & $-16151,56$ & $-2,95$ & $-0,0083 \%$ \\
\hline Itinerario III & 23214,74 & 127,00 & $-8880,01$ & $-14475,82$ & $-14,09$ & $-0,0607 \%$ \\
\hline Itinerario IV & 13515,89 & $-798,40$ & $-12010,15$ & $-709,98$ & $-2,63$ & $-0,0195 \%$ \\
\hline Itinerario $\mathrm{V}$ & 30425,55 & $-745,14$ & $-19897,72$ & $-9781,60$ & 1,09 & $0,0036 \%$ \\
\hline Itinerario VI & 10020,74 & $-3106,24$ & $-6256,69$ & $-649,07$ & 8,74 & $0,0872 \%$ \\
\hline Itinerario VII & 15968,03 & 1218,53 & $-7056,15$ & $-10131,00$ & $-0,60$ & $-0,0037 \%$ \\
\hline Itinerario VIII & 19471,00 & $-4806,32$ & $-9777,27$ & $-4883,39$ & 4,02 & $0,0206 \%$ \\
\hline TOTAL & 167985,03 & $-14942,16$ & $-88221,04$ & $-64828,73$ & $-6,91$ & $-0,0041 \%$ \\
\hline$\%$ sobre $\Delta \mathrm{CB}$ & & $-8,89 \%$ & $-52,52 \%$ & $-38,59 \%$ & & \\
\hline
\end{tabular}

Tabla 1. Superficies de los diferentes términos de la Eq. 1 en $\mathrm{m}^{2}$, desglosadas para los diferentes itinerarios mostrados en la Fig. 1. Las dos últimas columnas expresan el resultado del sumatorio de las columnas anteriores $(\triangle \mathrm{CB}-\triangle \mathrm{SP})$, en valor absoluto y en porcentaje respecto de $\triangle C B$. La última fila representa el porcentaje de las sumas de cada columna respecto de $\triangle C B$. Fuente: Elaboración propia.
Hay que insistir en que las cifras reflejadas en la Tabla 1 son cantidades globales que resumen un proceso complejo que no se puede comprender en su totalidad simplemente a partir de tales cifras. En lo que sigue las iremos desglosando concepto a concepto. El desglose de las magnitudes implicadas en el cálculo del incremento de vías ciclistas $\triangle$ CB se muestra en la Tabla 2. Como ya hemos indicado, la mayor parte de las vías ciclistas analizadas son vías segregadas del tráfico motorizado (la mayoría bidireccionales, pero algunas de ellas monodireccionales) con pavimento diferenciado tanto cuando discurren a nivel del acerado como de la calzada (Marqués, 2011). Solo un pequeño porcentaje de dichas vías ciclistas son "itinerarios ciclistas de prioridad peatonal”, señalizados sobre la acera mediante tachuelas metálicas y sin pavimento diferenciado (ver Figura 2). Por dichas vías los peatones tienen prioridad de paso y los ciclistas deben circular a velocidad moderada: menos de $10 \mathrm{~km} / \mathrm{h}$. La superficie dedicada a dichos itinerarios ciclistas se especifica con el símbolo IC en la Tabla. En esta se muestra, además, la superficie de las escasas vías ciclistas existentes previamente que no hemos podido analizar por carecer de datos con relación a los procesos de reurbanización implicados. A efectos de verificación, la sexta columna (Total $\mathrm{CB}$ ) es la suma de la segunda $(\triangle \mathrm{CB})$ y la quinta columnas (CB prev.), tal y como se muestra en la Eq. 2.

$$
\text { Total } \mathrm{CB}=\Delta \mathrm{CB}+\mathrm{CB} \text { prev. }
$$




\begin{tabular}{|c|c|c|c|c|c|c|}
\hline & $\Delta \mathbf{C B}\left(\mathbf{m}^{2}\right)$ & IC $\left(\mathbf{m}^{2}\right)$ & IC (\%) & CB prev. $\left(\mathbf{m}^{2}\right)$ & Total CB $\left(\mathbf{m}^{2}\right)$ & Longitud (m) \\
\hline Itinerario I & 19822,90 & 218,26 & $1,10 \%$ & 0,00 & 19822,90 & 9255,70 \\
\hline Itinerario II & 35546,17 & 2423,83 & $6,82 \%$ & 0,00 & 35546,17 & 16049,88 \\
\hline Itinerario III & 23214,74 & 0,00 & $0,00 \%$ & 0,00 & 23214,74 & 9620,80 \\
\hline Itinerario IV & 13515,89 & 0,00 & $0,00 \%$ & 0,00 & 13515,89 & 6415,02 \\
\hline Itinerario $\mathrm{V}$ & 30425,55 & 0,00 & $0,00 \%$ & 0,00 & 30425,55 & 14891,94 \\
\hline Itinerario VI & 10020,74 & 0,00 & $0,00 \%$ & 1242,02 & 11262,77 & 4961,24 \\
\hline Itinerario VII & 15968,03 & 230,01 & $1,44 \%$ & 0,00 & 15968,03 & 6557,99 \\
\hline \multirow[t]{2}{*}{ Itinerario VIII } & 19471,00 & 108,07 & $0,56 \%$ & 0,00 & 19471,00 & 8871,18 \\
\hline & 167985,03 & 2980,18 & $1,76 \%$ & 1242,02 & 169227,05 & 76623,76 \\
\hline
\end{tabular}

El desglose correspondiente a la superficie de acerado es algo más complejo. El incremento de las aceras $\Delta \mathrm{A}$ es el resultado de sumar, por un lado, los incrementos de acerado que resultaron tanto de convertir calzada en acera $(\triangle \mathrm{A}-\mathrm{C})$, como de convertir zonas sin pavimentar en acera $(\Delta \mathrm{A}-\mathrm{SP})$ y de restar a dicha suma los incrementos de vía ciclista que resultaron de convertir aceras en vías ciclistas $(\Delta \mathrm{CB}-\mathrm{A})$ y aceras en calzada $(\Delta \mathrm{C}-\mathrm{A})$ :

$$
\Delta \mathrm{A}=\Delta \mathrm{A}-\mathrm{C}+\Delta \mathrm{A}-\mathrm{SP}-\Delta \mathrm{CB}-\mathrm{A}-\Delta \mathrm{C}-\mathrm{A}
$$

Todas las magnitudes implicadas en la Eq. 3 se muestran en la Tabla 3. En la Tabla se muestra también la superficie dedicada a acerado compartido, donde la prioridad es del peatón, pero se permite la circulación de bicicletas. En ese caso se ha considerado que dicha superficie era y es acera, de modo que no computa a la hora de calcular $\Delta \mathrm{A}$.
Tabla 2. Desglose de las cantidades que dan lugar al incremento de vías ciclistas $\triangle C B$ mostrado en la Tabla 1. La tabla muestra la superficie correspondiente a los itinerarios ciclistas con prioridad de paso peatonal, en $\mathrm{m}^{2}$ y en porcentaje sobre el total de vías ciclistas (Total CB). Se muestra también la superficie de vías ciclistas construidas previamente y no incluidas en el análisis (CB prev.) y el total de vías ciclistas de la red (Total CB). La longitud se ha calculado con criterios puramente constructivos, de modo que cada vía ciclista construida cuenta una sola vez, ya sea mono o bidireccional. Fuente: Elaboración propia.

\begin{tabular}{|c|c|c|c|c|c|c|}
\hline & $\Delta \mathbf{A}\left(\mathbf{m}^{2}\right)$ & $\Delta \mathrm{A}-\mathrm{C}\left(\mathbf{m}^{2}\right)$ & $\Delta \mathrm{A}-\mathrm{SP}\left(\mathbf{m}^{2}\right)$ & $\Delta \mathrm{CB}-\mathrm{A}\left(\mathrm{m}^{2}\right)$ & $\Delta \mathbf{C}-\mathbf{A}\left(\mathbf{m}^{2}\right)$ & $\underset{\left(\mathbf{m}^{2}\right)}{\text { A Compartida }}$ \\
\hline Itinerario I & 3364,36 & 7440,59 & 3241,01 & 6916,04 & 401,20 & 0,00 \\
\hline Itinerario II & $-10195,95$ & 1348,94 & 0,00 & 11539,44 & 5,44 & 984,83 \\
\hline Itinerario III & 127,00 & 2906,26 & 8712,66 & 11059,51 & 432,40 & 8209,20 \\
\hline Itinerario IV & $-798,40$ & 5213,52 & 72,03 & 5492,68 & 591,27 & 0,00 \\
\hline Itinerario $\mathrm{V}$ & $-745,14$ & 4776,54 & 964,00 & 5993,62 & 492,07 & 793,87 \\
\hline Itinerario VI & $-3106,24$ & 2466,95 & 169,54 & 5517,91 & 224,83 & 1073,81 \\
\hline Itinerario VII & 1218,53 & 5556,62 & 0,00 & 4333,98 & 4,12 & 335,65 \\
\hline Itinerario VIII & $-4806,32$ & 4067,21 & 398,93 & 8836,80 & 435,67 & $1 v 748,62$ \\
\hline TOTAL & $-14942,16$ & 33776,64 & 13558,17 & 59689,98 & 2587,00 & 13145,98 \\
\hline
\end{tabular}

La Tabla 3 muestra que las repercusiones del proceso de reurbanización que condujo a la creación de la red de vías ciclistas de Sevilla fueron complejas. La superficie de acera directamente transformada en vía ciclistas fue significativa: $59689,98 \mathrm{~m}^{2}$ o $6 \mathrm{Ha}$ aproximadamente, lo que equivale al $36 \%$ del total de la superficie estrictamente ocupada por las vías ciclistas estudiadas. Sin embargo, esta superficie fue compensada en parte por nueva superficie de acerado, detraída princi-
Tabla 3. Desglose del incremento de aceras $\triangle \mathrm{A}$ como resultad de la conversión de calzada en acera $\triangle \mathrm{A}-\mathrm{C}$, de superficie sin pavimentar en acera $\triangle \mathrm{A}-\mathrm{SP}$, de acera en vía ciclista $\triangle C B-A$ y de acera en calzada $\triangle \mathrm{C}$-A. La última columna muestra la superficie de acera compartida. Fuente: Elaboración propia. 
palmente de la calzada (3 Ha), y de zonas sin pavimentar (1,4 Ha), de modo que el decremento de acerado neto fue de 1,5 Ha, equivalente al 9\% del total de la superficie dedicada a vías ciclistas. La Figura 3 ilustra la complejidad de estos procesos con un ejemplo concreto.

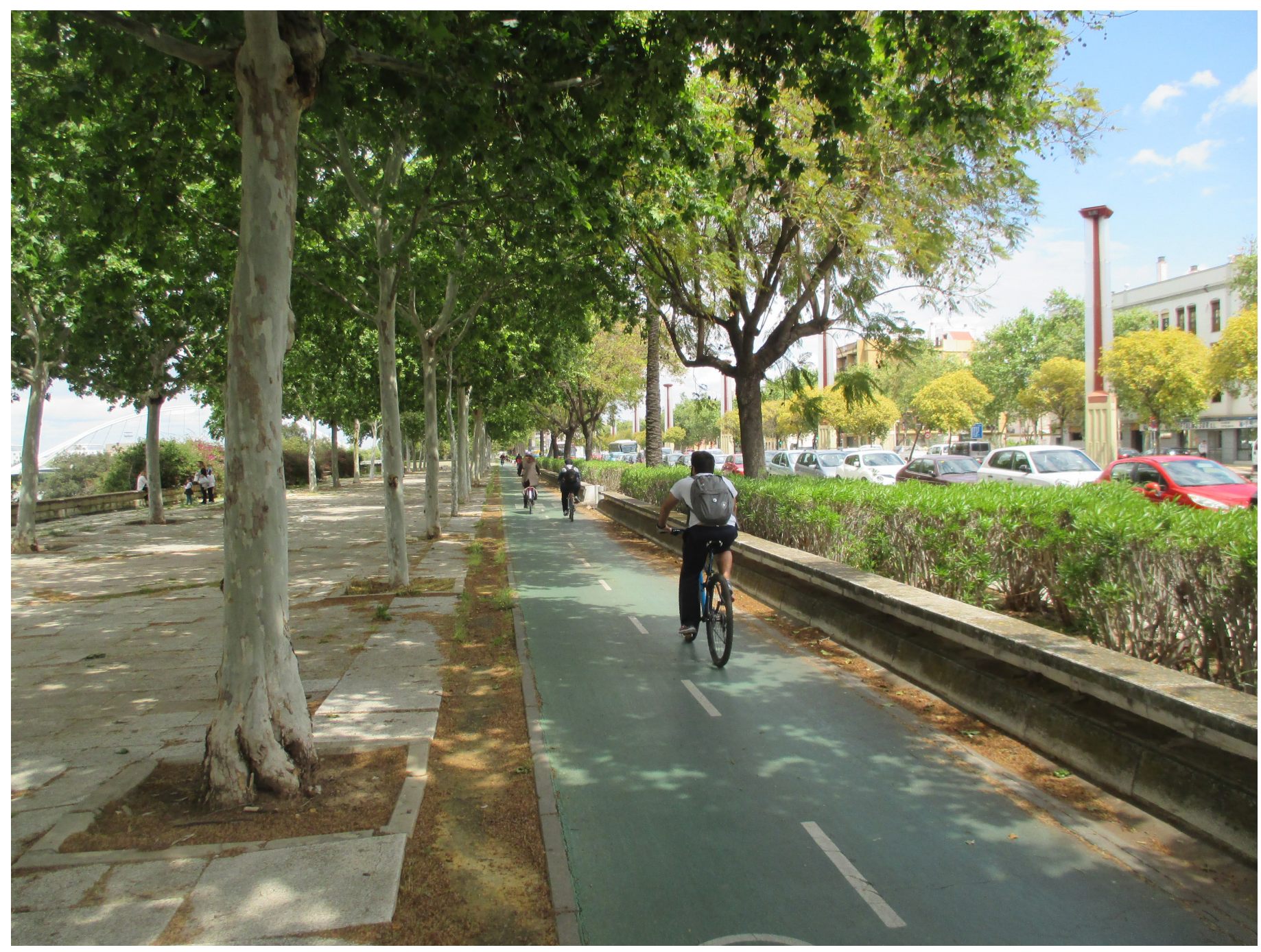

Figura 4. Vía ciclista realizada sobre acerado preexistente a lo largo de la calle Torneo (ltinerario II). Fuente: Elaboración propia.
Una discusión interesante es la calidad de los espacios peatonales detraídos y creados respectivamente. Muchos de los nuevos espacios peatonales creados son bandas de ancho reducido (menos de $1 \mathrm{~m}$ ) entre las nuevas vías ciclistas a nivel del acerado y la calzada, cuya utilidad para los peatones es dudosa y se reduce a ofrecerles cierta comodidad para acceder a los vehículos aparcados. Sin embargo, muchos de los espacios peatonales eliminados para crear vías ciclistas eran a su vez de escasa utilidad para los peatones como, por ejemplo, zonas entre alcorques o entre estos y la calzada, o también "orejas de burro" próximas a las intersecciones (A Contramano, 2009).

Por itinerarios, el que más zona peatonal neta detrajo fue el Itinerario II, especialmente en la parte de su recorrido que discurre en paralelo al río Guadalquivir (C/ Torneo), una zona que contaba y cuenta todavía en la actualidad con amplios acerados (ver Figura 4). El resto de los itinerarios supuso un decremento neto moderado del acerado (ver 2. a columna de la Tabla 3). En cuanto a la ocupación bruta de espacio peatonal (4. ${ }^{\mathrm{a}}$ columna de la Tabla 3$)$, el itinerario que más zona peatonal ocupó directamente para hacer la vía ciclista fue también el Itinerario II. Le sigue el Itinerario III, cuya ocupación de aceras se debe a 


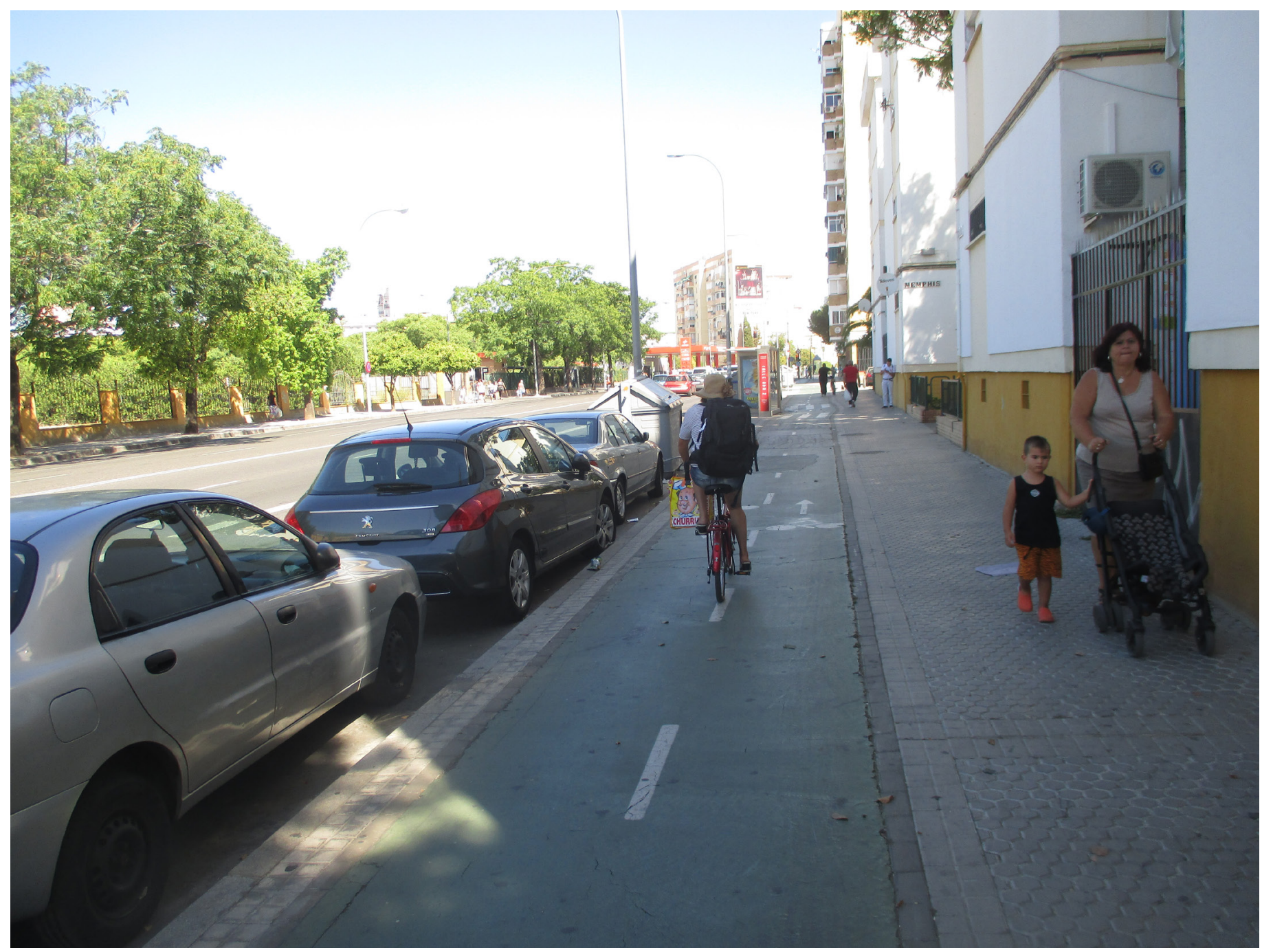

fundamentalmente a su paso por la Isla de la Cartuja, a través de zonas urbanizadas durante la Exposición Universal de 1992, una zona también con amplios acerados. Otro itinerario que implicó una ocupación bruta importante de acerado fue el Itinerario VIII, especialmente en el tramo entre la avenida de Andalucía y la avenida de Kansas City (vid. Figura 5), una zona densamente urbanizada en la que sería necesaria una reforma de la vía ciclista que implicara la recuperación y mejora de los acerados, sobre todo tratándose de un vial que cuenta en la actualidad con seis carriles de circulación más una banda de aparcamiento. Los ejemplos citados dan una idea de la diversidad de situaciones que se presentan en el análisis y de la dificultad para llegar a una conclusión cualitativa que tenga en cuenta no solo la cantidad sino también la "calidad" del espacio peatonal perdido.

El término $\Delta \mathrm{C}$ de la Tabla 1 corresponde al incremento de la calzada debido al proceso de reurbanización asociado a la creación de la red de vías ciclistas. Este término se puede desglosar de acuerdo con la Eq. 4:

$$
\Delta \mathrm{C}=\Delta \mathrm{C}-\mathrm{A}-\Delta \mathrm{A}-\mathrm{C}-\Delta \mathrm{CBN}-\mathrm{C}-\Delta \mathrm{CBI}-\mathrm{C} \quad(\mathrm{Eq} \cdot 4)
$$

Donde los dos primeros términos del sumatorio fueron ya incluidos en la Eq. 3 y se refieren a los intercambios de superficie entre acera y calzada. Los dos últimos términos de la Eq. 4, $\Delta \mathrm{CBN}-\mathrm{C}$ e $\Delta \mathrm{CBI}-\mathrm{C}$, se refieren ambos a la superficie de calzada transformada en vía ciclista. De
Figura 5. Vía ciclista realizada sobre acerado preexistente en la calle Ada, entre la avenida de Kansas City y la avenida de Andalucía (Itinerario VIII). Fuente: Elaboración propia. 
estos, $\triangle \mathrm{CBI}$-C se refiere a la superficie de vía ciclista señalizada sobre la calzada en las intersecciones e $\triangle \mathrm{CBN}-\mathrm{C}$ a la superficie de calzada reurbanizada para convertirla en tramos nuevos de vía ciclista entre las intersecciones. Todas estas magnitudes se muestran en la Tabla 4.

\begin{tabular}{|c|c|c|c|c|c|}
\hline & $\Delta \mathbf{C}\left(\mathbf{m}^{2}\right)$ & $\Delta \mathrm{C}-\mathrm{A}\left(\mathbf{m}^{2}\right)$ & $\Delta \mathrm{A}-\mathrm{C}\left(\mathbf{m}^{2}\right)$ & $\Delta \mathrm{CBN}-\mathrm{C}\left(\mathrm{m}^{2}\right)$ & $\Delta \mathrm{CBI}-\mathrm{C}\left(\mathbf{m}^{2}\right)$ \\
\hline Itinerario I & $-15141,43$ & 401,20 & 6916,04 & 6566,33 & 1535,70 \\
\hline Itinerario II & $-9201,62$ & 5,44 & 1348,94 & 5836,75 & 2021,38 \\
\hline Itinerario III & $-8880,01$ & 432,40 & 2906,26 & 4741,55 & 1664,61 \\
\hline Itinerario IV & $-12010,15$ & 591,27 & 5213,52 & 6070,77 & 1317,13 \\
\hline Itinerario V & $-19897,72$ & 492,07 & 4776,54 & 12970,29 & 2642,96 \\
\hline Itinerario VI & $-6256,69$ & 224,83 & 2466,95 & 3129,35 & 885,21 \\
\hline Itinerario VII & $-7056,15$ & 4,12 & 5556,62 & 777,67 & 725,98 \\
\hline Itinerario VIII & $-9777,27$ & 435,67 & 4067,21 & 4494,14 & 1651,58 \\
\hline TOTAL & $-88221,04$ & 2587,00 & 33252,08 & 44586,85 & 12444,55 \\
\hline
\end{tabular}

Tabla 4. Desglose de los incrementos en la calzada $\triangle \mathrm{C}$ asociados a la creación de las vías ciclistas. $\triangle \mathrm{C}$-A e $\triangle \mathrm{A}$-A fueron ya definidos en la Tabla 3. $\triangle \mathrm{CBN}-\mathrm{C}$ : Superficie calzada transformada en vía ciclista entre intersecciones. $\triangle \mathrm{CBI}-\mathrm{C}$ : Superficie de calzada señalizada como vía ciclista en las intersecciones.
Las cifras de la Tabla 4 ratifican, cuantificándola, la tesis que ya adelantábamos de un modo cualitativo en algunos trabajos previos (Marqués, 2011; Marqués et al., 2014; Marqués et al., 2015) de que la red de vías ciclistas se realizó mayoritariamente ocupando superficie de calzada. El resultado de las obras de reurbanización asociadas fue la "pérdida" de $88000 \mathrm{~m}^{2}$ de calzada, aproximadamente. Si de esta superficie total descontamos la superficie simplemente marcada en las intersecciones como vía ciclista, aún restan $76000 \mathrm{~m}^{2}$ o 7,6 Ha de superficie de calzada eliminadas, que es probablemente la cifra más relevante a los efectos de evaluar el impacto de la construcción de la red de vías ciclistas sobre la superficie urbana. Sabemos que dicha superficie proviene mayoritariamente de bandas de aparcamiento (Marqués, 2011) por lo que a razón de $10 \mathrm{~m}^{2}$ por plaza de aparcamiento podemos estimar en un máximo de 8000 las plazas de aparcamiento eliminadas, cifra que coincide con algunas estimaciones publicadas en la prensa (Valdés-Aragonés, 2014), aunque a este respecto es evidente que son necesarias más investigaciones antes de llegar a una estimación más precisa.

Hemos de insistir en que buena parte de la ocupación de espacio de calzada para crear vías ciclistas se realizó mediante la ampliación de la acera para la ubicación de la vía ciclista en este "nuevo acerado" (A Contramano, 2009; Marqués, 2011). A fin de ilustrar este proceso, en la Figura 6 se muestra el "antes" y el "después" de una de estas actuaciones, concretamente la ligada a la creación del carri-bici a lo largo de la calle Muñoz León, cerca de la intersección con la calle Madre Dolores Márquez, en la Ronda Histórica (Itinerario IV en Figura 1). Este tipo de actuaciones fueron más frecuentes incluso que la simple ubicación de la vía ciclista en la calzada, ilustrada en la Figura 2 (centro), lo que explica la aparente disparidad entre los porcentajes de aceras-bici y de ocupación de calzada ya mencionada.

El impacto neto de la construcción de la red de vías ciclistas sobre la superficie urbana sin pavimentar $\Delta$ SP se puede a su vez desglosar de acuerdo con la ecuación:

$$
\Delta \mathrm{SP}=-\Delta \mathrm{CB}-\mathrm{SP}-\Delta \mathrm{A}-\mathrm{SP}-\Delta \mathrm{CB}-\mathrm{SU} \quad(\mathrm{Eq} \cdot 5)
$$




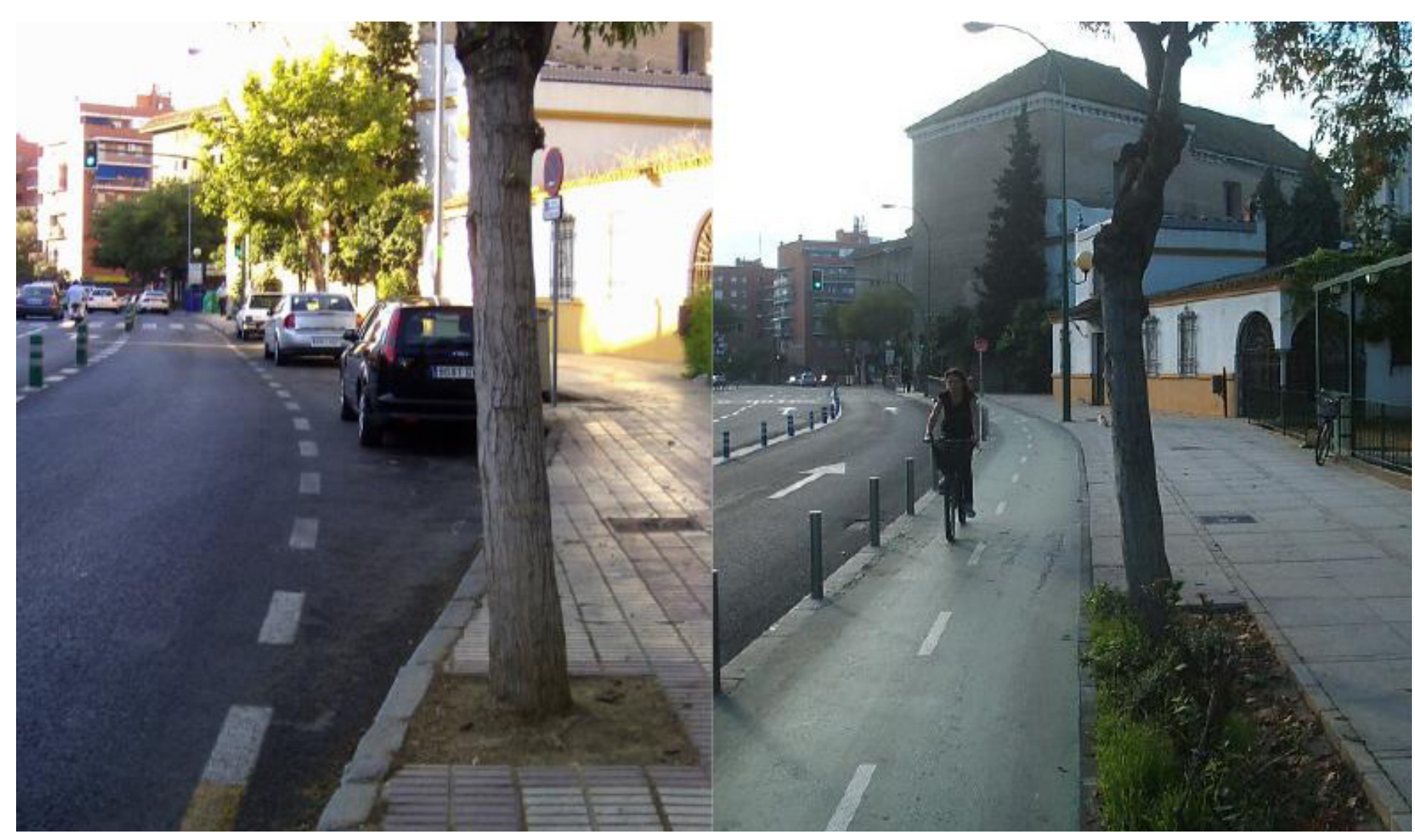

en la que $\Delta \mathrm{SP}$ es el incremento de suelo sin pavimentar que aparece en la Tabla 1, siendo $\Delta$ CB-SP el suelo urbano no pavimentado directamente utilizado en la construcción de vías ciclistas, $\triangle \mathrm{A}$-SP el incremento del acerado a partir de suelo urbano no pavimentado e $\Delta \mathrm{CB}-\mathrm{SU}$ la superficie de vías ciclistas construidas sobre suelo no urbanizado, en viario de nueva construcción. En este último caso simplemente se considera que toda la vía ciclista se construyó sobre suelo sin pavimentar sin hacer ningún otro tipo de consideración acerca de los posibles incrementos de calzada o acera, que se ignoran en el análisis por tratarse de suelo de nueva urbanización.
Figura 6. Situación antes y después de la creación de la vía ciclista en la calle Muñoz León, cerca de la intersección con la calle Madre Dolores Márquez. Fuente: Elaboración propia.

\begin{tabular}{|c|c|c|c|c|}
\hline $\mathbf{m}^{2}$ & $\Delta \mathbf{S P}\left(\mathbf{m}^{2}\right)$ & $\Delta \mathrm{CB}-\mathrm{SP}\left(\mathrm{m}^{2}\right)$ & $\Delta \mathrm{A}-\mathrm{SP}\left(\mathbf{m}^{2}\right)$ & $\Delta \mathrm{CB}-\mathrm{SU}\left(\mathbf{m}^{2}\right)$ \\
\hline Itinerario I & $-8046,33$ & 4077,57 & 3241,01 & 727,75 \\
\hline Itinerario II & $-16151,56$ & 7263,04 & 0,00 & 8888,51 \\
\hline Itinerario III & $-14475,82$ & 5651,18 & 8712,66 & 111,97 \\
\hline Itinerario IV & $-709,98$ & 637,95 & 72,03 & 0,00 \\
\hline Itinerario V & $-9781,60$ & 7424,89 & 964,00 & 1392,70 \\
\hline Itinerario VI & $-649,07$ & 479,53 & 169,54 & 0,00 \\
\hline Itinerario VII & $-10131,00$ & 10131,00 & 0,00 & 0,00 \\
\hline Itinerario VIII & $-4883,39$ & 4484,46 & 398,93 & 0,00 \\
\hline TOTAL & $-64828,73$ & 40149,62 & 13558,17 & 11120,94 \\
\hline
\end{tabular}

Tabla 5. Desglose de las superficies de suelo no pavimentado afectadas por la construcción de la red de vías ciclistas. $\triangle S P$ es el incremento neto de suelo sin pavimentar, $\triangle \mathrm{CB}-\mathrm{SP}$ el incremento de superficie de vía ciclista proveniente de suelo no pavimentado, $\triangle \mathrm{A}-\mathrm{SP}$ el incremento de acera (ya recogido en la Tabla 2) y $\triangle \mathrm{CB}-\mathrm{SU}$ la superficie de vías ciclistas construidas en nuevo viario, sobre terrenos sin urbanizar. Fuente: Elaboración propia. 
La Tabla 5 muestra las diferentes magnitudes incluidas en la Eq. 5. Desde el punto de vista de los trasvases de suelo urbanizado, la magnitud más relevante es la suma de la tercera y cuarta columna de la Tabla, $\Delta \mathrm{CB}-\mathrm{SP}+\Delta \mathrm{A}-\mathrm{SP}$, que cuantifica el total de suelo urbanizado sin pavimentar utilizado en la reurbanización, ya sea para crear vías ciclistas o aceras (no hemos detectado suelo sin pavimentar convertido en calzada, salvo en el nuevo viario). Esta suma asciende a $44000 \mathrm{~m}^{2}$ o 4,4 Ha aproximadamente y se corresponde en su mayor parte con la reducción de zonas terrizas (casi siempre albero) y algunas zonas ajardinadas a lo largo de las grandes avenidas que albergan las vías ciclistas de la red básica.

\section{Conclusiones}

Del análisis realizado se deduce que, cuantitativamente, la construcción de la red básica de vías ciclistas de Sevilla tuvo un impacto neto sobre la superficie total de vía pública que se tradujo mayoritariamente en la desaparición de espacio de calzada $(8,8 \mathrm{Ha}$, aproximadamente el $53 \%$ de la superficie total dedicada a vías ciclistas), seguida por una notable urbanización de superficie sin pavimentar $(4,4 \mathrm{Ha}, 38 \%$ de la superficie dedicada a vías ciclistas) y una pérdida de 1,5 Ha de superficie peatonal (mayoritariamente aceras) que supuso el $9 \%$ de la superficie de vías ciclistas generada. Globalmente considerados, estos resultados desmienten, más allá de situaciones concretas, el prejuicio de que las vías ciclistas de Sevilla se hicieron a costa fundamentalmente de aceras y zonas peatonales. Este prejuicio parece haber sido la consecuencia de la decisión que se tomó en su día de ubicar las vías ciclistas al nivel del acerado. Esta decisión, si bien pudo contribuir a generar una mayor sensación de seguridad entre los ciclistas noveles, contribuyendo de ese modo al éxito de uso de la infraestructura, desde el punto vista de la imagen social ha contribuido a generar la falsa idea de que dicho éxito se ha logrado a costa de la movilidad peatonal. En este sentido no cabe duda de que ha fallado la comunicación por parte del Ayuntamiento de Sevilla, que poco o nada ha hecho por contrarrestar esa imagen negativa: los únicos intentos al respecto han corrido a cargo de asociaciones no gubernamentales, como por ejemplo el estudio ya citado de la asociación A Contramano (2009).

Cuantitativamente, el impacto neto sobre el espacio dedicado a calzada incluye viario y aparcamiento en superficie y asciende, como ya hemos indicado, a 7,6 Ha cuando se detraen de las 8,8 Ha mencionadas las superficies ocupadas por las vías ciclistas en las intersecciones. En lo que respecta a estas 7,6 Ha, podemos afirmar que fueron fundamentalmente espacio de aparcamiento, por lo que la construcción de la red básica de vías ciclistas supuso la desaparición de miles de plazas de aparcamiento de automóviles. Comparativamente, el impacto neto sobre los espacios peatonales fue moderado $(1,5 \mathrm{Ha}, 9 \%$ de la superficie ocupada por las vías ciclistas de la red básica). En muchos casos se ocuparon acerados amplios, por lo que, en esos casos concretos, el impacto sobre la movilidad peatonal fue bajo o moderado. No obstante, en otros casos, se produjeron ocupaciones de acerado que haría falta recuperar, reubicando la vía ciclista sobre la calzada.

Hay que tener también en cuenta que Sevilla padece un problema crónico de escasez de espacios peatonales, por lo que, en ocasiones, del hecho de que la vía ciclista no haya ocupado espacio peatonal no se 
deduce que el espacio peatonal sea suficiente. En estos casos, la ubicación actual de muchas vías ciclistas al mismo nivel del acerado ofrece la oportunidad de resolver en parte el problema mencionado, trasladando la vía ciclista a la calzada y convirtiendo en acera el espacio actualmente ocupado por la vía ciclista. Desde nuestro punto de vista, esta sería, junto con la ya mencionada necesidad de una campaña explicativa por parte del Ayuntamiento, una de las recomendaciones más importantes que cabría deducir de nuestro estudio.

Uno de los resultados más relevantes de este trabajo ha sido la elaboración de una base de datos cartográfica, de momento limitada a la red básica de vías ciclistas de Sevilla, pero que podría extenderse a la totalidad de la red ciclista sin dificultad, donde se han recogido en detalle las afecciones sobre las diferentes categorías de espacio urbano consideradas - calzada, acera y espacio sin pavimentar - de las vías ciclistas. Consideramos que esta base de datos ofrece un buen punto de partida para la planificación futura de la red viaria de la ciudad y puede contribuir a solucionar o paliar muchos de los problemas detectados a lo largo de estos últimos años en relación con la red de vías ciclistas de Sevilla y su interacción con otras redes de movilidad urbana, tanto peatonal como motorizada. Asimismo, la metodología seguida para la elaboración de dicha base de datos pensamos que podría aplicarse también al análisis de procesos similares en otras ciudades. 


\section{Referencias}

A Contramano: Asamblea Ciclista de Sevilla (2009). ¿Quitó el carril-bici espacio al peatón? Informe sobre el trazado de la vía ciclista sobre la Ronda Histórica de Sevilla. Recuperado el 21 de junio de 2017 de: http:/ / www.acontramano.org/index.php?option=com_ joomdoc\&task=document.download\&path=acontr amano \% 2Fsevilla \% 2Fiquito-el-carril-bici-espacio-alpeaton \&Itemid $=62$.

Agencia de Ecología Urbana de Barcelona (2007). Plan Especial de Indicadores de Sostenibilidad Ambiental de la Actividad Urbanistica de Sevilla. Sevilla: Ayuntamiento de Sevilla.

Ayuntamiento de Sevilla (2006). Desplazamientos en bicicleta: conteos en 24 puntos de observación. Sevilla: Ayuntamiento de Sevilla.

- (2006b). Plan General de Ordenación Urbana. Sevilla: Ayuntamiento de Sevilla. Recuperado el 21 de junio de 2017 de: http:/ /www.pgou.eu/Sevilla.htm.

- (2007). Plan de la Bicicleta de Sevilla 2007-2010. Sevilla: Ayuntamiento de Sevilla. Recuperado el 21 de junio de 2017 de: http:/ /www.sevilla.org/sevillaenbici/plandirector/PlanBiciSevilla.html.

- (2007b). Cuantificación de bicicletas en los itinerarios de la nueva red de vías ciclistas de Sevilla.

- (2008). Desplazamientos en bicicleta en la red de vías ciclistas de Sevilla. Conteo en 42 puntos de observación. Sevilla: Ayuntamiento de Sevilla.

- (2010). Estudio sobre el uso de la bicicleta en la ciudad de Sevilla. Sevilla: Ayuntamiento de Sevilla. Recuperado el 21 de junio de 2017 de: http://www.sevilla. org/sevillaenbici/pdf/Investigacion \%20Uso\%20Bicicletas\%20Ene-2010.pdf.

- (2013). Tipología de las Vias Ciclistas de Sevilla. Sevilla: Ayuntamiento de Sevilla. Recuperado el 21 de junio de 2017 de: http://www.sevilla.org/sevillaenbici/Pdf/tipologia_vias_ciclistas.pdf.

Castillo-Manzano, J.I. y Sánchez-Braza, A. (2013). Can anyone hate the bicycle? The hunt for an optimal local transportation policy to encourage bicycle usage. Environmental Politics, 22 (6), 1010-1028.

- (2013). Managing a smart bicycle system when demand outstrips supply: the case of the university community in Seville. Transportation, 40 (2), 459-477.

Castillo-Manzano, J.I., López-Valpuesta, L. y MarchenaGómez, M. (2015). Seville: A city with two souls. Cities, 42, 142-151.

Castillo-Manzano, J.I., Castro-Nuño, M. y López-Valpuesta, L. (2015). Analyzing the transition from a public bicycle system to bicycle ownership: A complex relationship. Transportation Research Part D: Transport and Environment, 38, 15-26.

Chong, S. et al. (2010). Relative injury severity among vulnerable non-motorised road users: comparative analysis of injury arising from bicycle-motor vehicle and bicycle-pedestrian collisions. Accident Analysis E Prevention, 42 (1), 290-296.

Dirección General de Tráfico (2010). Accidentes de Tráfico en Zona Urbana en España. Madrid: DGT. Recuperado el 21 de junio de 2017 de: http:/ / www.dgt. es/Galerias/seguridad-vial/estadisticas-e-indicadores/publicaciones/accidentes-urban/accidentes_ trafico005.pdf.

Fernánez-Heredia, A., Lorenzi, E. y Sánchez-Llorca, A. (2014). Influencia de la participación ciudadana en las políticas de movilidad ciclista: un estudio comparado de Madrid y Sevilla. XVIII Congreso Panamericano de Ingeniería de Transito, Transporte y Logística. Recuperado el 21 de junio de 2017 de: http:/ / ciclopart.redcimas.org/wp-content/ uploads/2014/03/PANAM_2014_Heredia_Lorenzi_Sanchez.pdf.

Forester, J. (2001). The Bicycle Transportation Controversy. Transportation Quarterly, 55 (2), 7-17.

Gerencia de Urbanismo (1993). Plan Especial de la Bicicleta. Sevilla: Ayuntamiento de Sevilla.

Herlihy, D.V. (2004). Bicycle: the history. Yale: Yale University Press.

Horton, D. (2007). Fear of cycling. Cycling and society. Oxford: Ashgate.

Huerta, E. y Hernández-Ramírez, M. (2015). Etnografía de la bicicleta en Sevilla. DAPS- Informes y documentos de trabajo, 6. Recuperado el 21 de junio de 2017 de: https:/ / rio.upo.es/xmlui/handle/10433/1425.

López-Valpuesta, L. y Sánchez-Braza, A. (2016). Going a long way? On your bike! Comparing the distances for which public bicycle sharing system and private bicycles are used. Applied Geography, 71, 95-105.

Malpica-Soto, P. (2010). Los ciclistas en Sevilla como nuevo grupo urbano emergente, $X$ Congreso Español de Sociología. Recuperado el 21 de junio de 2017 de: http:/ / docplayer.es/9362723-Los-ciclistas-en-sevillacomo-nuevo-grupo-urbano-emergente.html.

Marqués, R. (2011). Sevilla: una experiencia exitosa de promoción de la movilidad en bicicleta en el Sur de Europa. Hábitat y Sociedad, 3, 107-130.

- (2017). La importancia de la bicicleta. Sevilla: Ed. Universidad de Sevilla.

Marqués, R., Hernández-Herrador, V. y Calvo-Salazar, M. (2014). Sevilla: a successful experience of bicycle promotion in a mediterranean context. The Sustainable City IX. Urban Regeneration and Sustainability, 1, 769-781.

- (2015). How infrastructure can promote cycling in cities: Lessons from Seville. Research in Transportation Economics, 53, 31-44. 
Marqués, R. et al. (2015b). When cycle paths are not enough: Seville's bicycle-PT project. Urban Transport XXI, 146, 79-91.

Marqués, R. y Hernández-Herrador, V. (2017). On the effect of networks of cycle-tracks on the risk of cycling. The case of Seville. Accident Analysis EF Prevention, 102, 181-190.

Mateos A., Sanz, A. y Torres, C. (1987). Estudio Sobre Actuaciones y Políticas de Potenciación de la Bicicleta en el Área Urbana de Sevilla. Sevilla: Ayuntamiento de Sevilla.

Morales, L. (2011). La movilidad ciclista como factor de sostenibilidad: breve análisis de su emergencia en la ciudad de Sevilla. Hábitat y sociedad, 2, 109-130.

Parody, S. (2011). Comportamiento y evolución del transporte no contaminante en Sevilla. La movilidad sostenible en bicicleta. Trabajo de fin de carrera. Licenciatura en Geografía, Universidad de Sevilla. Recuperado el 21 de junio de 2017 de: http:/ /www.acontramano.org/ index.php?option $=$ com_joomdoc\&task=document. download\&path=otros-documentos-deinteres \% 2Fsevilla\% 2Fmovilidad-ciclista-en-sevilla-laeficiencia-del-carril-bici\&Itemid=62.
SIBUS: Sistema Integral de la Bicicleta de la Universidad de Sevilla (2012). Estudio sobre el uso de la bicicleta en Sevilla, 2011. Sevilla: Universidad de Sevilla. Recuperado el 21 de junio de 2017 de: http:/ / bicicletas.us.es/Sevilla2011.pdf.

- (2014). Evaluación del uso de la bicicleta en Sevilla. Noviembre de 2013. Sevilla: Universidad de Sevilla. Recuperado el 21 de junio de 2017 de: http://bicicletas.us.es/Sevilla2013.pdf.

- (2016). Análisis sobre la movilidad ciclista en Sevilla. Año 2015. Sevilla: Universidad de Sevilla. Recuperado el 21 de junio de 2017 de: http:/ / bicicletas. us.es/Sevilla2015.pdf.

Ministry of Transport, Public Works and Water Management (1999). The Dutch Bicycle Master Plan. Description and evaluation in an historical context. Amsterdam: Ministry of Transport, Public Works and Water Management.

Valdés-Aragonés, I. (2014). Sevilla, paraíso de las dos ruedas. El País Semanal, 11 de mayo de 2014. Recuperado el 21 de junio de 2017 de: http:/ / elpais.com/elpais/2014/05/07/eps/1399465309_221018.html.

Hernández-Herrador, V. y Marqués, R. (2017). El impacto del "Carril-Bici" de Sevilla sobre el espacio urbano de la ciudad: un análisis preliminar. Hábitat y Sociedad, 10, 181-202.

<http://dx.doi.org/10.12795/HabitatySociedad.2017.i10.11> 


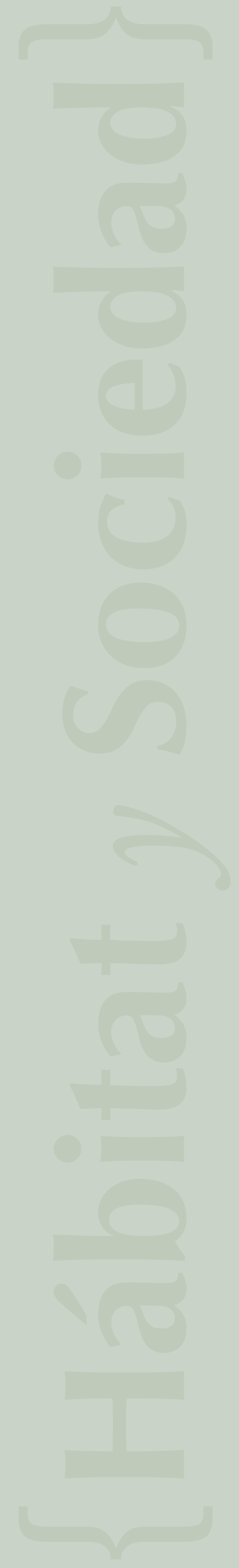

